\title{
STOPP-START Medication Review: A Non-Randomized Trial in an Indonesian Tertiary Hospital to Improve Medication Appropriateness and to Reduce the Length of Stay of Older Adults
}

\author{
Fauna Herawati' (iD, Ida Bagus Nyoman Maharjana², \\ Tuty Kuswardhani ${ }^{3}$, and Astrid Pratidina Susilo'
}

\begin{abstract}
Background: Inappropriate prescribing may lead to medication errors among older adults. Pharmacists can curb the occurrences of these errors by conducting medication reviews. Screening Tool of Older Person's Prescriptions (STOPP) or Screening Tool to Alert doctors to Right Treatments (START) may curb the incidence of adverse drug reactions and improve medication appropriateness by providing guides about when particular types of medications should be started or stopped. Objective: This study aimed to evaluate the use of STOPP/START to improve the Adapted Medication Appropriateness Index (MAl), to reduce the risk of ADRs (GerontoNet score), and length of stay (LOS). Setting: Geriatric Inpatient Ward, Sanglah General Hospital, Bali, Indonesia. Method: A non-randomized controlled trial was conducted in older adults (>60years) who were selected consecutively from inpatient units in a tertiary hospital in Bali, Indonesia. The intervention group received medication reviews by pharmacists in collaboration with physicians to assess its appropriateness with STOPP/START criteria on admission and during their stay at the hospital. The control group obtained standard care. Main Outcome Measures: The outcomes were measured using the Adapted MAI, GerontoNet Score, and LOS. Results: Thirty patients in the intervention group and 33 patients in the control group were included in this study. The adapted MAI was 2.97 (2.25) and 9.94 (6.I4) with $P<.00$ I. The GerontoNet score was 3.33 (2.28) and 5.18 (2.10) with $P=.003$, LOS was 7.63 (3.00) days and I4.I8 (9.97) days with $P=.01$ I, respectively. Conclusion: The use of STOPP/START as a tool for medication review improved medication appropriateness and reduced ADR risk and LOS.
\end{abstract}

\section{Keywords}

STOPP/START, adverse drug reactions, drug/medical use evaluation, geriatrics, older adult, medication therapy management

Lay tittle: STOPP-START medication review.

Lay summary: Medication review with STOPP-START is developed for older adults. Chronic diseases and polypharmacy add the burden to elderly health. STOPP-START medication review will help stop unnecessary or harmful medication, propose to start any medicine that needed, and therefore increase the medication appropriate index and patient safety.

\section{Introduction}

United Nations Economic and Social Commission for Asia and the Pacific (ESCAP) stated that in 2016, approximately $12.4 \%$ of the population in the region was 60 years or older with the increasing projection to more than a quarter or
1.3 billion people by $2050 .{ }^{1}$ The percentages vary, however, across regions. By 2050, over a third of the population is expected to be 60 years or older in East and North Asia. In North and Central Asia, 1 in 4 persons will be 60 years or older. The number of older adults in Indonesia will continue to increase, with a population explosion projected at $414 \%$ from 1990 to 2025. Indonesia was ranked 4th, after China,

'University of Surabaya, Surabaya, Indonesia

${ }^{2}$ Udayana University, Kabupaten Badung, Bali, Indonesia

${ }^{3}$ Sanglah General Hospital, Kota Denpasar, Bali, Indonesia

Corresponding Author:

Fauna Herawati, Faculty of Pharmacy, University of Surabaya, Jalan Raya Kalirungkut, FF Building, 5th Floor, Surabaya 60293, Indonesia.

Email: fauna@staff.ubaya.ac.id 
India, and the United States, as it has the most populated older adults (around $6 \%$ of 267 million people). ${ }^{2}$

Older adults often suffer from multiple chronic diseases that need multiple medications. They experience changes in pharmacokinetics and pharmacodynamics due to the physiological aging process and become susceptible to drugrelated problems such as drug interactions, adverse drug reactions, poor compliance, and inappropriate medication..$^{3-9}$ Inappropriate medication can cause medication error, which is mostly preventable ${ }^{10-13}$ by a collaborative healthcare team's medication review. ${ }^{14-16}$

Medication reviews reduce not only the number of medication errors but also increases patient satisfaction and treatment outcomes. ${ }^{17}$ In older adults, medication errors occur at different phases of care (prescribing, dispensing, and administration) at a hospital or in a community setting. ${ }^{13,16}$ Older adults need thorough monitoring and seamless care related to their physiological changes and susceptibility to chronic diseases. ${ }^{15,18,19}$ Prescribing errors can trigger other errors. Inappropriate Prescribing (IP) is one of the errors triggered by prescribing errors and is considered a severe problem in the pharmacotherapy of older adults, such as adverse drug events (ADEs). ${ }^{20} \mathrm{ADEs}$ may increase healthcare costs, length of stay (LOS), or hospital readmission. ${ }^{21,22}$ Pharmacists can play essential roles in the medication reviews. ${ }^{23-25}$

STOPP/START, Beers criteria, and the Systematic Tool to Reduce Inappropriate Prescribing (STRIP) are examples of tools for medication reviews in older adults. The STOPP/ START criteria are more useful to detect potentially inappropriate medication (PIM) in the hospital setting. ${ }^{26-28}$ Meanwhile, Beers criteria are more suitable for home care or outpatient settings. ${ }^{28}$ The STRIP is a better fit for medication reviews in a primary care setting. ${ }^{29}$

Although often used in different contexts, there are several disadvantages to Beers' criteria. First, Beers criteria lacked data on the prevention of ADEs or costs. ${ }^{26,27,30,31}$ Second, for acute hospital care, STOPP criteria can detect $35 \%$ of potentially inappropriate medication (PIM), where a third is related to ADEs. Beers can only detect $25 \%$ PIM, where a quarter is related to ADEs. Data showed that the STOPP criteria detected ADEs that contribute to acute hospitalization in older adults 2.8 times more than the Beers criteria. ${ }^{22}$ Third, in the daily clinical practice of Indonesia, where this study took place, more than $50 \%$ of drugs in the Beers' criteria are not available, such as trimethobenzamide, metaxalone, amphetamine, methocarbamol, cyclobenzaprine, xaprozin, carisoprodol, and thioridazine.

The STOPP/START criteria are developed based on therapeutic evidence in older adults. Medication reviews with STOPP/START improved rational drug use, prevent adverse drug events, and improve health outcome of older adults. ${ }^{27}$ STOPP/START criteria have been used in several hospital settings for older adults with chronic kidney diseases, ${ }^{32}$ cardiac diseases, ${ }^{33}$ diabetes, ${ }^{34}$ psychiatric disorders, ${ }^{35,36}$ or multiple myeloma. ${ }^{37}$ Medication review with STOPP/ START can minimize potential prescribing omissions (PPOs), ${ }^{32,34}$ drug-related problems (DRPs), and potentially inappropriate medications (PIMs). ${ }^{33,34}$ In the psychiatric setting, STOPP/START criteria reduce adverse drug reaction of anticholinergics, benzodiazepines, antipsychotics, and opioids through deprescribing. ${ }^{35,36}$

Nevertheless, there are some gaps in the current evidence of the implementation of STOPP/START. Most studies on STOPP/START assessed the prescribing quality and numbers of the drug-related problem. Only a few of them also reported patient-related outcomes. There are 4 randomized clinical trials included in a meta-analysis, only 2 out of 4 measured patient's length of stay as their secondary outcome, and only one study reported the incidence of selected geriatric syndromes. ${ }^{37}$ In Indonesia, where our study took place, evidence on STOPP/START was limited. We found only 2 studies on STOPP/START from 2 hospitals in East Java ${ }^{38}$ and South Sumatera. ${ }^{39}$

Another gap is that most studies reported that the medication reviews were not conducted collaboratively between pharmacists and physicians. In most studies, pharmacists performed the reviews as a single profession and communicated the results to the physicians. ${ }^{37}$ In one study, STOPP/ START criteria were applied by a physician without the involvement of pharmacists. ${ }^{37}$

Our study aimed to evaluate the effectiveness of STOPP/ START as a guide for medication review STOPP/START criteria in an inpatient geriatric care service in Indonesia. The criteria were implemented in a collaborative geriatric team consisting of physicians and pharmacists. We evaluated the adapted Medication Appropriateness Index (MAI), the risk of ADR (GerontoNet score), and the length of stay (LOS) as the outcomes. This study took place in Indonesia, where evidence on STOPP/START was limited. The implementation of STOPP/START criteria is needed because the published clinical practice guidelines usually accommodate recommendations for an adult patient, not specific for geriatric.

\section{Method}

\section{Study Context}

This study was conducted at a 700-bed tertiary care accredited hospital, Sanglah General Hospital, Denpasar, Bali. The regulation in this hospital stated that the standard care of older adults ( $>60$ years) with 2 or more degenerative chronic diseases and geriatric syndromes were cared for by the geriatric team. This standard care aimed to provide holistic service involving an interprofessional collaborative team consisting of geriatric specialists, pharmacists, nutritionists, physiotherapists, and other consulting physicians. As a part of a collaborative geriatric team, the pharmacists perform medication review. 


\section{Study Design}

This study was a non-randomized controlled trial. The intervention group received medication reviews using STOPP/ START criteria, while the control group received standard care.

In the intervention group, the pharmacist and the physicians applied the STOPP/START criteria in a collaborative fashion. The pharmacists took the patient's medication history and clinical information, assessed medication appropriateness and potential adverse drug risks, and discussed them with the geriatricians. This medication review is categorized as a type 3 review by The Pharmaceutical Care Network Europe. ${ }^{40}$

The primary outcome measure of this study was adapted Medication Appropriateness Index (MAI); the secondary outcomes were GerontoNet ADR risk score and the length of stay (LOS).

The group allocation was based on the different wards: one ward for the intervention group and another for the control group. As each ward had different teams of health professionals, contaminations between groups could be averted. Prior to this study, one of the researchers $(\mathrm{MH})$ introduced STOPP/START to the team members in the intervention group's ward. The STOPP criteria consist of 65 recommendations to avoid prescribing potentially inappropriate drugs; while the START criteria consist of 22 recommendations to prescribe drug therapy related to their system organ disorders $^{41,42}$ (Supplemental Appendix 1). One pharmacist for each ward was assigned to conduct medication reviews. The physicians in group interventions have agreed to discuss the pharmacist's recommendations based on the medication review. The team in the control group, from the other ward, was not aware of STOPP/START medication review. Thus, they used drug use guidelines for adults.

\section{Study Participants}

This study population was older adults who were admitted to Sanglah General Hospital, Denpasar. Subjects were selected consecutively according to the following criteria. The inclusion criteria were older adults $(>60$ years old) who were hospitalized with a non-emergency degenerative disease or non-acute infection sepsis diagnosis, received polypharmacy (with 5-7 drugs), ${ }^{30,31}$ and used national or district health financing coverage. The exclusion criteria were patients admitted to hospital for chemotherapy or laboratory examinations, or patients who had severe conditions, that is, terminal illness or vegetative conditions. The dropout criteria were a patient's death during hospital admission, patients' withdrawal from the study, or discontinuation of care due to self-discharge or referral to other healthcare facilities. For a small effect size $(0.2)$, a trial with $90 \%$ power, and 2 -sided $5 \%$ significance, a minimum of 25 samples per treatment arm were required. . $^{42,43}$

\section{Data Collection}

The data of the patients were recorded in a case report form (CRF) throughout their stay in the hospital (from admission until discharge). The medication review was drawn from medication history, patient information, and clinical information. The outcome measurements were adapted Medication Appropriateness Index (MAI), GerontoNet ADR risk score, and length of stay (LOS).

Adapted MAI was assessed from the CRF. The original MAI consisted of 10 items with the scale of 1 through $3 .{ }^{44}$ The recently validated and adapted MAI consists of 8 criteria of therapeutic indications, drug selection, dose, route of administration, drug interactions, drug-disease interactions, duration of therapy, and undesirable drug reactions/ adverse drug reaction (ADR) with a maximum value of 16 per drug item (Supplemental Appendix 2). ${ }^{45}$ Incorrect doses, potential drug interactions, drug interactions possibility with clinical conditions, and potential adverse drug reactions were scored 2 . The incorrect routes and duration of therapy were scored 1. Appropriateness in all 8 criteria was scored 0 . The MAI assessment was conducted according to Internal Medicine Diagnosis and Therapeutic Guidelines at Sanglah Hospital, the clinical pathway at Sanglah Hospital, Geriatric Dosage Handbook, and British National Formulary.

The GerontoNet score was an assessment of the ADR risk in the older adults consisting of the number of drugs, the previous ADR experienced, presence of heart failure, liver disease, presence of 4 or more comorbidities, and presence of kidney failure. ${ }^{46}$ Data for The GerontoNet score assessment was taken from the case report form (CRF). The data of patients' length of stay (LOS) were also recorded from the medical record.

Before the data collection, we ensured inter-rater reliability for the assessment of MAI and GerontoNet score. We aimed for a good agreement of the Kappa value $>0.6$. For the MAI assessment, we measured the Kappa agreement by comparing 2 pharmacists and 2 doctors. The MAI inter-rater reliability test showed good agreement between pharmacists (Kappa 0.868), and moderate agreement between pharmacists and doctors (Kappa 0.747 and 0.620). For the GerontoNet score, the Kappa agreement was obtained by comparing the assessment of the 3 pharmacists with the Kappa of 0.630 and 0.759 , showing moderate agreement.

\section{Data Analysis}

These outcome variables (MAI, GerontoNet ADR risk score, LOS) were drawn from case report form (CRF) and assessed by 2 pharmacists who had been previously trained in clinical pharmacy. An independent party removed patient identity and group allocation information. Thus, both assessors were not aware of the group allocation. 


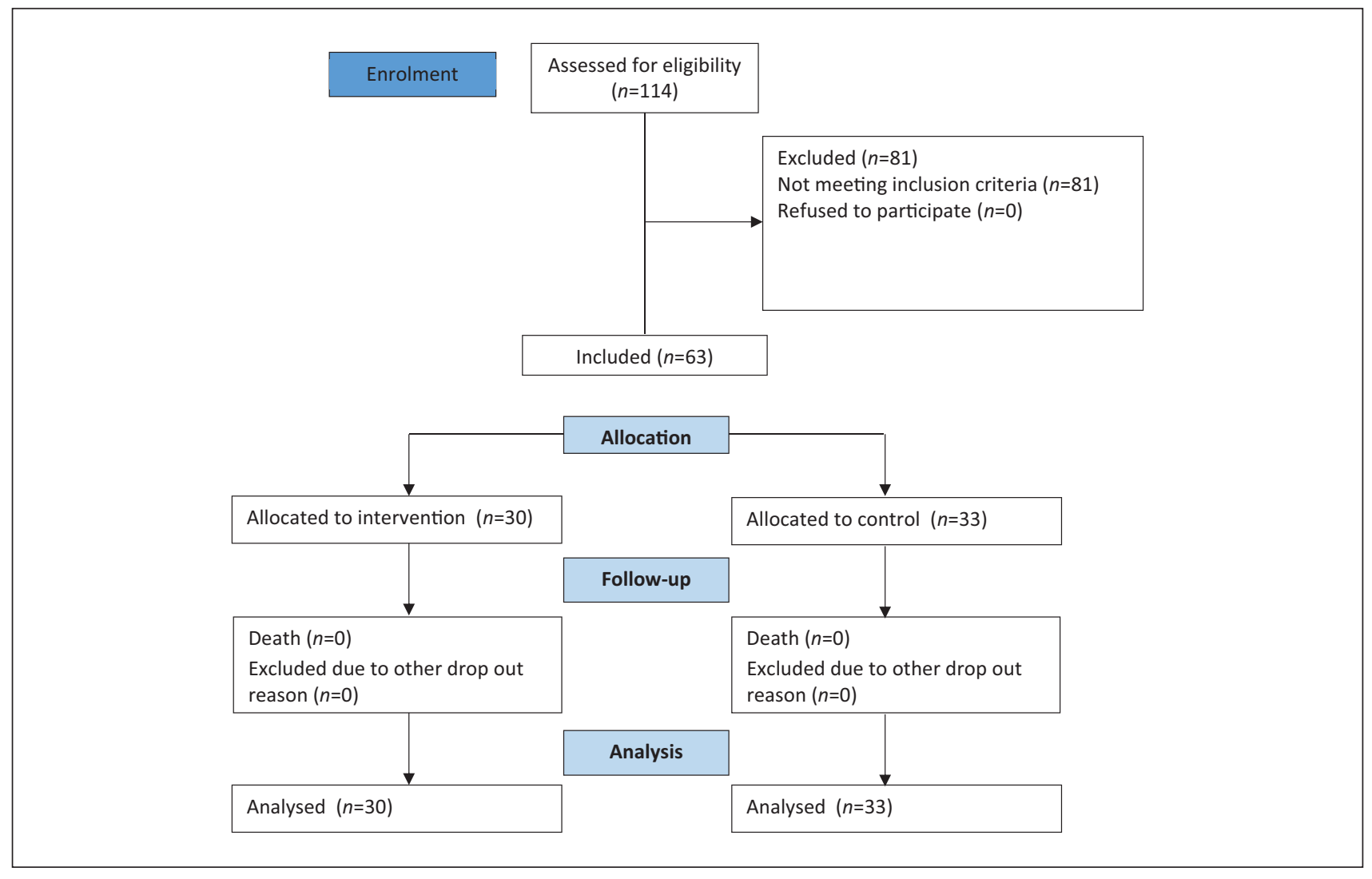

Figure I. Participant flow diagram.

The outcome measure in this study, that is, adapted MAI, GerontoNet score, and LOS were analyzed with independent $t$-test or Mann-Whitney test, if the data were not normally distributed. Categorical data were analyzed with the chisquare test.

\section{Ethical Consideration}

The ethical clearance of the study (No. 678/UN.14.2/ Litbang/2013) was granted by the independent ethical committee. The study was approved by the hospital director board and in concordance with the Indonesian Law for the Protection of Personal Data and the Declaration of Helsinki. Information were provided to the participants before they agreed to join the study and signed the informed consent forms. Participants are free to withdraw their participation throughout the study period. To ensure confidentiality, patients' identities were removed from the analysis and the reports.

\section{Results}

There are 144 elderly patients in the 3 months of study periods. One hundred and forty-four older patients were transferred from the emergency unit to the inpatient ward. Only 63 patients met the inclusion criteria: 30 patients in the intervention group and 33 other patients in the control group. All patients were followed up until each of them was discharged. None of them dropped out of the study. The flow of the participant is presented in Figure 1.

The characteristics of the subjects are presented in Table 1. In this study, all patients were non-emergency cases; nor an acute state of any comorbidities, including acute infection(s). The mean age of the subjects in the intervention group was significantly higher than one in the control group. Gender, number of co-morbidity, and the number of polypharmacy were comparable in both groups. More than $30 \%$ of the patients had cardiovascular disease, respiratory disease, or renal impairment. Sixteen percent of patients had 7 drugs during their stay at the hospital.

The baseline MAI differences between the intervention 3.30 (2.09) and the control group 3.27 (2.50) were not statistically significant $(P>.05)$. Whereas the MAI assessment of the patient at the time of discharge differed significantly between the two groups: 2.97 (2.25) in the intervention group and 9.94 (6.14) in the control group (Table 2). Within 3 months, there were 43 recommendations for STOPP criteria and 49 recommendations for START criteria (Table 3). As agreed, physicians in the intervention groups discussed and 
Table I. Patient Characteristics.

\begin{tabular}{|c|c|c|c|}
\hline Characteristic & $\begin{array}{l}\text { Intervention group } \\
\qquad(N=30)\end{array}$ & $\begin{array}{l}\text { Control group } \\
\qquad(\mathrm{N}=33)\end{array}$ & $P$ value \\
\hline Age $(\text { mean })^{\mathrm{a}}$ & $72.5(9.2)$ & $67.8(4.8)$ & .01 \\
\hline Gender & & & .12 \\
\hline Male & $17(56.7 \%)$ & $25(75.8 \%)$ & \\
\hline Female & $13(43.3 \%)$ & $8(24.2 \%)$ & \\
\hline \multicolumn{4}{|l|}{ Comorbidity } \\
\hline Cardiovascular disease & $13(43.3 \%)$ & $22(66.7 \%)$ & \\
\hline Neurological disorders & $3(10 \%)$ & $4(12.1 \%)$ & \\
\hline Gastrointestinal disorders & $12(40 \%)$ & 7 (2l.2\%) & \\
\hline Respiratory diseases & $14(46.7 \%)$ & $10(30.3 \%)$ & \\
\hline Musculoskeletal disorders & $2(6.7 \%)$ & I (3.0\%) & \\
\hline Endocrine diseases & $9(30 \%)$ & $8(24.2 \%)$ & \\
\hline Renal impairment & $9(30 \%)$ & II (33.3\%) & \\
\hline Urogenital diseases & $2(6.7 \%)$ & $6(18.2 \%)$ & \\
\hline Liver impairment & $2(6.7 \%)$ & $0(0 \%)$ & \\
\hline \multicolumn{4}{|c|}{ Number of comorbid per patient } \\
\hline 1 & $5(16.7 \%)$ & $8(24.2 \%)$ & .76 \\
\hline 2 & $16(53.3 \%)$ & $16(48.5 \%)$ & \\
\hline$\geq 3$ & $9(30 \%)$ & $9(27.3 \%)$ & \\
\hline \multicolumn{4}{|c|}{ Polypharmacy (number of medication) } \\
\hline 5 & $18(60 \%)$ & $22(66.7 \%)$ & .85 \\
\hline 6 & $7(23.3 \%)$ & $6(18.2 \%)$ & \\
\hline 7 & 5 (16.7\%) & 5 (I5.2\%) & \\
\hline
\end{tabular}

${ }^{\text {a} A g e ~ w a s ~ r e p o r t e d ~ i n ~ m e a n ~(S D) . ~}$

accepted pharmacists' recommendations in the intervention group; the prescribers in the intervention group accepted the pharmacist recommendation. Forty-four percent (19/43) of accepted STOPP recommendations were stopping the use of calcium channel blockers in a patient with chronic constipation (10/43) and substitute systemic corticosteroids with an inhaled corticosteroid in COPD patients $(9 / 43)$. There were 10 out of 49 accepted START recommendations to initiate aspirin or clopidogrel in patients with atherosclerotic coronary and sinus rhythm.

There was also a significant difference in the GerontoNet score of the two groups at the time of discharge: 3.33 (2.28) in the intervention group and 5.18 (2.10) in the control group (the higher score indicates a higher risk of ADR as shown in (Table 2). The length of stay of the patient admitted in the study period is 14.2 (10.0) days (control group), longer than the length of stay of patients in the intervention group 7.6 (3.0) days (Table 2). The ADR occurrence in the control group is higher than one in the intervention group (Table 4).

\section{Discussion}

The prevalence of potentially inappropriate medication (PIM) prescribed in older adults is high. ${ }^{47,48}$ The older adults, frequently with multiple comorbidities, obtain prescriptions from multiple physicians. Consequently, this polypharmacy leads to more harms than benefits that may require further hospital admission. ${ }^{49}$

Hospital pharmacy practice for clinical pharmacy services includes medication review ${ }^{50,51}$ and the pharmacists should provide an evidenced-based therapeutic recommendation for the health care team. In Indonesia, a pharmacist-led medication review process is the standard care of pharmaceutical services, ${ }^{52}$ but the implementation varied across hospitals. For older adults, the pharmacists use STOPP/START criteria as a guideline to stop or start medication. This study showed that the use of STOPP/START criteria offered several beneficial outcomes, such as increasing medication appropriateness, minimizing adverse drug events, and decreasing the length of stay. Besides medication appropriateness review during the patient stay at the hospital, the clinical pharmacy role should expand to reconciliation medication on admission and discharge.

Our study showed that the use of STOPP/START could improve the MAI during hospital treatment. The result was consistent with other studies on medication review using STOPP/START. ${ }^{28,37,41,44}$ One study of the medication review effectiveness (using STOPP/START) on MAI showed an improved MAI score of up to 2.8 (95\% CI 2.2-3.8) in the intervention group with the absolute risk reduction of $35.7 \%$ (95\% CI 26.3-44.9). ${ }^{51}$

Onder et al in Italy validated the GerontoNet score as a tool to assess ADR risk in older adults. The number of drugs and 
Table 2. The Improvement Outcome From Admission to Discharge.

\begin{tabular}{|c|c|c|c|}
\hline Variables & Intervention group $(\mathrm{N}=30)$ & Control group $(\mathrm{N}=33)$ & $P$ value \\
\hline Medication Appropriateness Index score (mean) & & & $<.001$ \\
\hline Before intervention & $3.3(2.1)$ & $3.3(2.5)$ & \\
\hline After intervention & $3.0(2.3)$ & $9.9(6.1)$ & \\
\hline GerontoNet score (mean) & $3.3(2.3)$ & $5.2(2.1)$ & .003 \\
\hline $0-2$ & $13(43.3 \%)$ & $4(12.1 \%)$ & \\
\hline $3-5$ & II (36.7\%) & $13(39.4 \%)$ & \\
\hline$>5$ & $6(20.0 \%)$ & $16(48.5 \%)$ & \\
\hline Length of stay (mean) & 7.6 days $(3.0)$ & I4.2 days $(10.0)$ & .011 \\
\hline $0-7$ & $17(56.7 \%)$ & $13(39.4 \%)$ & \\
\hline $8-14$ & $12(40.0 \%)$ & $8(24.2 \%)$ & \\
\hline$|5-2|$ & I (3.3\%) & $3(9.1 \%)$ & \\
\hline$>21$ & $0(0 \%)$ & $9(27.3 \%)$ & \\
\hline
\end{tabular}

Table 3. STOPP and START Recommendation.

\begin{tabular}{|c|c|c|c|}
\hline \multicolumn{2}{|l|}{ STOPP recommendation $\left(\mathrm{N}^{\mathrm{a}}=30\right)$} & \multicolumn{2}{|c|}{ START recommendation $\left(\mathrm{N}^{\mathrm{a}}=30\right)$} \\
\hline Total (n) & 33 & Total (n) & 47 \\
\hline A. Cardiovascular system & 17 & A. Cardiovascular system & 27 \\
\hline $\mathrm{A} 0 \mathrm{I}$ & I & $\mathrm{A} 02$ & I \\
\hline A02 & I & $\mathrm{A} 03$ & 8 \\
\hline $\mathrm{A} 03$ & I & $\mathrm{A} 04$ & 6 \\
\hline $\mathrm{A} 04$ & I & A05 & 3 \\
\hline A08 & 10 & A06 & 3 \\
\hline $\mathrm{A} 12$ & 2 & $\mathrm{~A} 07$ & 2 \\
\hline Al7 & I & $\mathrm{A} 08$ & 2 \\
\hline \multirow[t]{3}{*}{ B. Central nervous system (B02) } & 2 & B. Central nervous system & 5 \\
\hline & & BOI & 2 \\
\hline & & B02 & 3 \\
\hline \multicolumn{2}{|l|}{ C. Gastrointestinal system (C05) } & C. Gastrointestinal system & 0 \\
\hline D. Respiratory system (D02) & 6 & D. Respiratory system (DOI) & 2 \\
\hline \multirow{3}{*}{$\begin{array}{l}\text { E. Musculoskeletal system } \\
\text { E0I } \\
\text { E02 }\end{array}$} & 4 & E. Musculoskeletal system & 4 \\
\hline & 1 & E02 & I \\
\hline & 3 & E03 & 3 \\
\hline \multirow[t]{5}{*}{ F. Urogenital system } & 0 & F. Endocrine system & II \\
\hline & & FOI & 4 \\
\hline & & F02 & 3 \\
\hline & & F03 & I \\
\hline & & F04 & 3 \\
\hline G. Endocrine system (G02) & 1 & & \\
\hline \multirow{3}{*}{$\begin{array}{l}\text { H. Drugs that adversely affect those prone to falls } \\
\mathrm{HOI} \\
\mathrm{H} 03\end{array}$} & 2 & & \\
\hline & I & & \\
\hline & 1 & & \\
\hline
\end{tabular}

${ }^{\mathrm{a}} \mathrm{N}$ was the number of patients in the intervention group.

previous ADR events history was the strongest predictors of subsequent $\mathrm{ADR}$, followed by heart failure, liver disease, 4 or more comorbidities, and kidney failure. The Gerontonet score in the Onder et al study showed that the receiver operating characteristic (ROC) curve for predicting ADR risk is 0.71 (95\% CI, 0.68-0.73). ${ }^{46}$ Our study proved that medication review with STOPP/START could improve the GerontoNet score associated with an increased risk of occurrence ADR in older adults during hospital admission. The number of participants who experienced ADR in the control group was almost 4 times the same as in the intervention group.

The length of stays of inpatient in the hospital was varied, related to any factor, such as transfer and discharge delay time, the number of diagnosis and severity, the number of adverse 
Table 4. Adverse Drug Event.

\begin{tabular}{lccc}
\hline & $\begin{array}{c}\text { Intervention group } \\
(\mathrm{N}=30)\end{array}$ & $\begin{array}{c}\text { Control group } \\
(\mathrm{N}=33)\end{array}$ & $\begin{array}{c}\mathrm{P} \text { value } \\
\text { Total }(\mathrm{n})\end{array}$ \\
$\begin{array}{l}\text { Cough } \\
\text { Blood pressure increase }\end{array}$ & $0(0 \%)$ & $\mathrm{I}(3.0 \%)$ \\
$>20 \mathrm{~mm} \mathrm{Hg}$ & $1(3.3 \%)$ & $3(9.1 \%)$ \\
Blood pressure $<100 \mathrm{~mm} \mathrm{Hg}$ & & & .017 \\
Gastrointestinal bleeding & $0(0 \%)$ & $1(3.0 \%)$ \\
Hyperkalemia & $0(0 \%)$ & $2(6.1 \%)$ \\
Hypokalemia & $1(3.3 \%)$ & $2(6.1 \%)$ \\
Hypersensitivity & $0(0 \%)$ & $2(6.1 \%)$ \\
Constipation & $2(6.7 \%)$ & $0(0 \%)$ \\
\hline
\end{tabular}

drug event, including the insurance type. ${ }^{53}$ Our study showed that the average LOS in the control group (14.2 \pm 10.0 days) was longer than the intervention group (7.6 \pm 3.0 days $)$, with the mean LOS difference of 6.55 days. A descriptive and exploratory analysis from a database of (53965) patients admitted to a tertiary general university hospital in South Korea showed that the patients' median length of hospital stay was 9 days for geriatric center admissions. ${ }^{53}$ In Vetrano et al study, average LOS in patients admitted through elective admission was 12.0 (6.7) days. ${ }^{54}$ LOS is an outcome related to hospitalization costs. ${ }^{55}$ Research showed that every 1-day reduction in LOS could save about $3 \%$ of the total hospital costs. ${ }^{56}$ Reduction in length of hospital stay (LOS) is a potential strategy to optimize resource consumption and reduce health care costs. Nevertheless LOS can be influenced by other factors other than comorbidity and polypharmacy, such as the frequency of adverse drug events. ${ }^{57}$ The ADE occurrence in the control group was significantly higher than in the intervention group, and therefore, it might have contributed to the difference of LOS between groups.

The education for pharmacists and physicians regarding the implementation of the STOPP/START criteria for medication review for all older adults is essential and urgent. ${ }^{58}$ The use of STOPP/START should also be supported by interprofessional collaboration in the geriatric team to positively impact professional satisfaction, patient satisfaction, health care quality, and patient outcome. ${ }^{59}$ The prescribers in the intervention group followed all the recommendations because there is an agreement before the study. In a real setting, the accepted rate may vary. The sound collaboration and intensive discussions between the pharmacists and the physicians may improve this acceptance rate.

\section{Study Limitations}

This study has several limitations. First, randomization was not conducted because the patient allocation was based on admission to the ward. This approach was selected to mask the intervention and to ensure that the healthcare team in the control group were not aware of the implementation of
STOPP/START criteria. We minimized confounding by applying the inclusion and exclusion criteria to ensure that both groups were comparable. Unfortunately, patients in intervention groups were significantly older than one in control groups. When patients were getting older, they were more susceptible to comorbidities and polypharmacy. $3,4,8,9$ Consequently, we might expect a worse health outcome in the intervention groups. Contradictory, our studies showed that the adapted MAI, GerontoNet, and LOS in the intervention group were better than the control group.

Second, the descriptive data showed differences between groups in the type of comorbidities. For example, the percentage of patients with cardiovascular diseases in the control group was higher than the intervention groups, while the percentage of patients with respiratory diseases and gastrointestinal disorders were higher in the intervention groups. Nevertheless, the overall number of comorbidities and polypharmacy was not significantly different. There are 63 patients; every patient had 1 to 5 comorbidities that may interplay to influence the health outcomes. Studies showed that the strongest predictor of LOS among older adults was polypharmacy. Other predictors reported in different studies were pressure ulcers, cerebrovascular disease, and dementia. ${ }^{54}$

Third, we calculated our sample based on the MAI, as the primary outcome. We did not power our study to the GerontoNet score and LOS. Many variables are influencing the length of stay. Further research with a larger sample size to minimize the uncertainty of the length of stay result is needed.

Finally, we selected patients consecutively in 3 months in a single hospital in Bali, Indonesia. Thus, the result of the sample represented the target population, which might be homogeneous in the term of culture, within the study period. Further study for a more extended period is needed to avoid potential seasonal variation ${ }^{60}$ or to explore the possibility of generalization in other population or cultural contexts.

\section{Conclusion}

Medication review with STOPP/START criteria can improve the adapted Medication Appropriateness Index and reducet 
ADR risks and the length of stay. There is a need to introduce STOPP/START criteria to pharmacists and physicians through continuing educational support. A better collaboration of pharmacists and physicians in the clinical practice is essential to improve the quality of daily care for older adults.

\section{Acknowledgments}

The authors wish to thank: the clinical pharmacist Anita Irawan, S.Farm., M.Farm., Apt. for her support in the process of medication review, the geriatric team of the Sanglah General Hospital, and the patients involved in the study.

\section{Declaration of Conflicting Interests}

The author(s) declared no potential conflicts of interest with respect to the research, authorship, and/or publication of this article.

\section{Funding}

The author(s) received no financial support for the research, authorship, and/or publication of this article.

\section{ORCID iD}

Fauna Herawati (iD https://orcid.org/0000-0002-8355-955X

\section{Supplemental Material}

Supplemental material for this article is available online.

\section{References}

1. United Nations ESCAP, Social Development Division. 2016 Population Data Sheet. United Nations ESCAP; September 9, 2016 revision

2. Populationof.Net. Indonesia population. Accessed May 27, 2019. https://www.populationof.net/indonesia/

3. Halter JB, Ouslander JG, Tinetti ME, Studenski S, High KP, Asthana S, eds. Hazzard's Geriatric Medicine and Gerontology. 6th ed. Washington, DC: McGraw-Hill Companies, Inc.; 2009.

4. Rahmawati F, Nurrochmah H, Wasilah R, Sulaiman SAS. Potentiality of drug-drug interaction in hospitalized geriatric patients in a private hospital, Yogyakarta, Indonesia. Asian $J$ Pharm Clin Res. 2010;3(3):191-194.

5. Kulkarni V, Bora SS, Sirisha S, Saji M, Sundaran S. A study on drug-drug interactions through prescription analysis in a South Indian teaching hospital. Ther Adv Drug Saf. 2013;4(4):141146. doi: $10.1177 / 2042098613490009$

6. Bucşaa C, Farcaşa A, Cazacua I, et al. How many potential drug-drug interactions cause adverse drug reactions in hospitalized patients?. Eur J Intern Med. 2013;24(1):27-33.

7. Dumbreck S, Flynn A, Nairn M, et al. Drug-disease and drugdrug interactions: systematic examination of recommendations in 12 UK national clinical guidelines. BMJ. 2015;350:h949. doi:10.1136/bmj.h949

8. Shah BM, Hajjar ER. Polypharmacy, adverse drug reactions, and geriatric syndromes. Clin Geriatr Med. 2012;28:173-186. doi:10.1016/j.cger.2012.01.002

9. Teka F, Teklay G, Ayalew E, Teshome T. Potential drugdrug interactions among elderly patients admitted to medical ward of Ayder Referral Hospital, Northern Ethiopia: a cross sectional study. BMC Res Notes. 2016;9(1):431. doi:10.1186/ s13104-016-2238-5

10. Keers RN, Williams SD, Cooke J, Ashcroft DM. Causes of medication administration errors in hospitals: a systematic review of quantitative and qualitative evidence. Drug Saf. 2013;36(11):1045-1067. doi:10.1007/s40264-013-0090-2

11. Tariq RA, Scherbak Y. Medication errors. In: StatPearls [Internet]. Treasure Island, FL: StatPearls Publishing; 2019. Accessed May 25, 2020. https://www.ncbi.nlm.nih.gov/books/ NBK519065/

12. Wheeler AJ, Scahill S, Hopcroft D, Stapleton H. Reducing medication errors at transitions of care is everyone's business. Aust Prescr. 2018;41(3):73-77.

13. Metsälä E, Vaherkoski U. Medication errors in elderly acute care-a systematic review. Scand J Caring Sci. 2014;28(1): 12-28. doi:10.1111/scs. 12034

14. da Silva BA, Krishnamurthy M. The alarming reality of medication error: a patient case and review of Pennsylvania and National data. J Community Hosp Intern Med Perspect. 2016;6(4):31758. doi:10.3402/jchimp.v6.31758

15. Lavan AH, Gallagher PF, O'Mahony D. Methods to reduce prescribing errors in elderly patients with multimorbidity. Clin Interv Aging. 2016;11:857-866. doi:10.2147/CIA.S80280

16. Christensen M, Lundh A. Medication review in hospitalised patients to reduce morbidity and mortality. Cochrane Database Syst Rev. 2016;2:CD008986. doi:10.1002/14651858. CD008986.pub3

17. Kianmehr N, Mofidi M, Saidi H, Hajibeigi M, Rezai M. What are patients' concerns about medical errors in an Emergency Department?. Sultan Qaboos Univ Med J. 2012;12(1):86-92.

18. Bahrani L, Eriksson T, Höglund P, Midlöv P. The rate and nature of medication errors among elderly upon admission to hospital after implementation of clinical pharmacist-led medication reconciliation. Eur J Hosp Pharm. 2014;21(3): 156-160.

19. Pepa PA, Langley-DeGroot MH, Rule OS. Prescribing cascade in a geropsychiatric patient: a slippery slope. J Geriatr Ment Health. 2018;5(1):62-64. doi:10.4103/jgmh.jgmh_17_17

20. Morimoto T, Gandhi TK, Seger AC, Hsieh TC, Bates DW. Adverse drug events and medication errors: detection and classification methods. Qual Saf Health Care. 2004;13(4): 306-314.

21. Klopotowska JE, Wierenga PC, Stuijt CCM, et al. Adverse drug events in older hospitalized patients: results and reliability of a comprehensive and structured identification strategy. PLoS ONE. 2013;8(8):e71045. doi:10.1371/journal.pone.0071045

22. Nachtigall A, Heppner HJ, Thürmann PA. Influence of pharmacist intervention on drug safety of geriatric inpatients: a prospective, controlled trial. Ther Adv Drug Saf. 2019;10:2042098619843365. doi:10.1177/2042098619843365

23. Rollason V, Vogt N. Reduction of polypharmacy in the elderly: a systematic review of the role of the pharmacist. Drugs Aging. 2003;20(11):817-832. doi:10.2165/00002512-20032011000003

24. Hailu BY, Berhe DF, Gudina EK, Gidey K, Getachew M. Drug related problems in admitted geriatric patients: the impact of clinical pharmacist interventions. BMC Geriatr. 2020;20(13):18. doi: $10.1186 / \mathrm{s} 12877-020-1413-7$

25. Gallagher PF, O'Mahony D. STOPP (Screening Tool of Older Persons potentially inappropriate Prescriptions): application to 
acutely ill elderly patients and comparison with Beers criteria. Age Ageing. 2008;37(6):673-679.

26. O'Mahony D, O'Sullivan D, Byrne S, O'Connor MN, Ryan C, Gallagher P. STOPP/START criteria for potentially inappropriate prescribing in older people: version 2. Age Ageing. 2015;44(2):213-218. doi:10.1093/ageing/afu145

27. Varallo FR, Capucho HC, Planeta CS, Mastroianni PC. Safety assessment of potentially inappropriate medications (PIM) use in older people and the factors associated with hospital admission. J Pharm Pharmaceu Sci. 2011;14(2):283-290.

28. Fick DM, Cooper JW, Wade WE, Waller JL, Maclean JR, Beers $\mathrm{MH}$. Updating the Beers criteria for potentially inappropriate medication use in older adults: results of a US consensus panel of experts. Arch Intern Med. 2003;163(22):2716-2724.

29. Meulendijk MC, Spruit MR, Drenth-van Maanen AC, et al. Computerized decision support improves medication review effectiveness: an experiment evaluating the STRIP assistant's usability. Drugs Aging. 2015;32(6):495-503. doi:10.1007/ s40266-015-0270-0

30. Gallagher PF, O'Connor MN, O'Mahony D. Prevention of potentially inappropriate prescribing for elderly patients: a randomized controlled trial using STOPP/START criteria. Clin Pharmacol Ther. 2011;89(6):845-854.

31. Chang CB, Chen JH, Wen CJ, et al. Potentially inappropriate medications in geriatric outpatients with polypharmacy: application of six sets of published explicit criteria. Brit J Clin Pharmacol. 2011;72(3):482-489.

32. Parker K, Bull-Engelstad I, Benth JŠ, et al. Effectiveness of using STOPP/START criteria to identify potentially inappropriate medication in people aged $\geq 65$ years with chronic kidney disease: a randomized clinical trial. Eur J Clin Pharmacol. 2019;75(11):1503-1511. doi:10.1007/s00228-01902727-9

33. Mekdad SS, Alsayed AA. Quality Improvement project to reduce drug-related problems (DRPs) and potentially inappropriate medications (PIMs) in Geriatrics Cardiac Clinic in Saudi Arabia. Can Geriatr J. 2019;22(2):49-54. doi:10.5770/ cgj. 22.338

34. Williams S, Miller G, Khoury R, Grossberg GT. Rational deprescribing in the elderly. Ann Clin Psychiatry. 2019;31(2):144152.

35. Umıt EG, Baysal M, Bas V, Asker I, Kırkızlar O, Demır AM. Polypharmacy and potentially inappropriate medication use in older patients with multiple myeloma, related to fall risk and autonomous neuropathy. J Oncol Pharm Pract. 2019;26(1): 43-50. doi:10.1177/1078155219835303

36. Siripala UGS, Premadasa SPK, Samaranayake NR, Wanigatunge CA. Usefulness of STOPP/START criteria to assess appropriateness of medicines prescribed to older adults in a resource-limited setting. Int J Clin Pharm. 2019;41(2):525530. doi:10.1007/s11096-019-00786-7

37. Hill-Taylor B, Walsh KA, Stewart S, Hayden J, Byrne S, Sketris IS. Effectiveness of the STOPP/START (Screening Tool of Older Persons' potentially inappropriate Prescriptions/ Screening Tool to Alert doctors to the Right Treatment) criteria: systematic review and meta-analysis of randomized controlled studies. J Clin Pharm Ther. 2016;41(2):158-169. doi:10.1111/jept.12372

38. Julaiha S. Identifikasi potentially inappropriate medications (PIMs) berdasarkan kriteria STOPP START pada pasien geriatri rawat inap di RS Advent Bandar Lampung. Jurnal Analis Kesehatan. 2018;7(1):657-665.

39. Fitriah N. Analisis penggunaan obat pada pasien geriatri Rawat Jalan Poli Jantung RSD Dr. Soebandi Jember dengan Metode STOPP START [undergraduate theses]. Jember: Universitas Jember; 2018.

40. Pharmaceutical Care Network Europe. Statement on Medication Review 2013. Zuidlaren: PCNE; 2013.

41. Gallagher PF, Ryan C, Byrne S, Kennedy J, O’Mahony D. STOPP (Screening Tool of Older Person's Prescriptions) and START (Screening Tool to Alert doctors to Right Treatment). Consensus validation. Int J Clin Pharmacol Ther. 2008;46(2):72-83.

42. O'Connor MN, Gallagher P, O’Mahony D. Inappropriate prescribing criteria, detection and prevention. Drugs Aging. 2012;29(6):437-452.

43. Whitehead AL, Julious SA, Cooper CL, Campbell MJ. Estimating the sample size for a pilot randomised trial to minimise the overall trial sample size for the external pilot and main trial for a continuous outcome variable. Stat Methods Med Res. 2016;25(3):1057-1073.

44. Hanlon JT, Schmader KE. The medication appropriateness index at 20: where it started, where it has been, and where it may be going. Drugs Aging. 2013;30(11):893-900. doi:10.1007/ s40266-013-0118-4

45. Nair NP, Chalmers L, Peterson GM, Bereznicki BJ, Castelino RL, Bereznicki LR. Hospitalization in older patients due to adverse drug reactions - the need for a prediction tool. Clin Interv Aging. 2016; 11:497-505.

46. Onder G, Petrovic M, Tangiisuran B, et al. Development and validation of a score to assess risk of adverse drug reactions among in-hospital patients 65 years or older. Arch Intern Med. 2010;170(13):1142-1148.

47. Page RL 2nd, Linnebur SA, Bryant LL, Ruscin JM. Inappropriate prescribing in the hospitalized elderly patient: defining the problem, evaluation tools, and possible solutions. Clin Interv Aging. 2010;5:75-87.

48. Tokuda Y. Polypharmacy, inappropriate prescribing and adverse drug events in Japan. J Gen Fam Med. 2016;17(1):3-4.

49. Pérez T, Moriarty F, Wallace E, McDowell R, Redmond P, Fahey T. Prevalence of potentially inappropriate prescribing in older people in primary care and its association with hospital admission: longitudinal study. BMJ. 2018;363:k4524. doi:10.1136/bmj.k4524

50. Silva ROS, Macêdo LA, Santos GAD Jr, Aguiar PM, de Lyra DP Jr. Pharmacist-participated medication review in different practice settings: service or intervention? An overview of systematic reviews. PLoS ONE. 2019;14(1):e0210312. doi:10.1371/journal.pone. 0210312

51. Geurts MM, Talsma J, Brouwers JR, de Gier JJ. Medication review and reconciliation with cooperation between pharmacist and general practitioner and the benefit for the patient: a systematic review. Br J Clin Pharmacol. 2012;74(1):16-33. doi:10.1111/j.1365-2125.2012.04178.x

52. Indonesian Ministry of Health. Standar pelayanan kefarmasian di rumah sakit. Jakarta, Indonesia: Indonesian Ministry of Health; 2016. Accessed July 26, 2019. https://www.persi.or.id/ images/regulasi/permenkes/pmk722016.pdf

53. Baek H, Cho M, Kim S, Hwang H, Song M, Yoo S. Analysis of length of hospital stay using electronic health 
records: a statistical and data mining approach. PLOS ONE. 2018;13(4):e0195901. doi:10.1371/journal.pone.0195901

54. Vetrano DL, Landi F, De Buyser SL, et al. Predictors of length of hospital stay among older adults admitted to acute care wards: a multicentre observational study. Eur J Intern Med. 2014;25:56-62.

55. Bailey JG, Davis PJ, Levy AR, Molinari M, Johnson PM. The impact of adverse events on health care costs for older adults undergoing nonelective abdominal surgery. Can J Surg. 2016;59(3):172-179. doi:10.1503/cjs.013915

56. Barnes DE, Palmer RM, Kresevic DM, et al. Acute care for elders units produced shorter hospital stays at lower cost while maintaining patients' functional status. Health Aff (Millwood). 2012;31(6):1227-1236. doi:10.1377/hlthaff.2012.0142
57. Calderón-Larrañaga A, Poblador-Plou B, González-Rubio F, Gimeno-Feliu LA, Abad-Díez JA, Prados-Torres A Multimorbidity, polypharmacy, referrals, and adverse drug events: are we doing things well?. Br J Gen Pract. 2012;62(605): e821-e826. doi:10.3399/bjgp12X659295

58. Francis J, Abraham S. Clinical pharmacists: bridging the gap between patients and physicians. Saudi Pharm J. 2014; 22(6):600-602. doi:10.1016/j.jsps.2014.02.011

59. Tsakitzidis G, Timmermans O, Callewaert N, et al. Outcome indicators on interprofessional collaboration interventions for elderly. Int J Integr Care. 2016;16(2):5.

60. Mathieson K. Making sense of biostatistics: types of nonprobability sampling. J Clin Res Best Pract. 2014;10(10):1-2. 


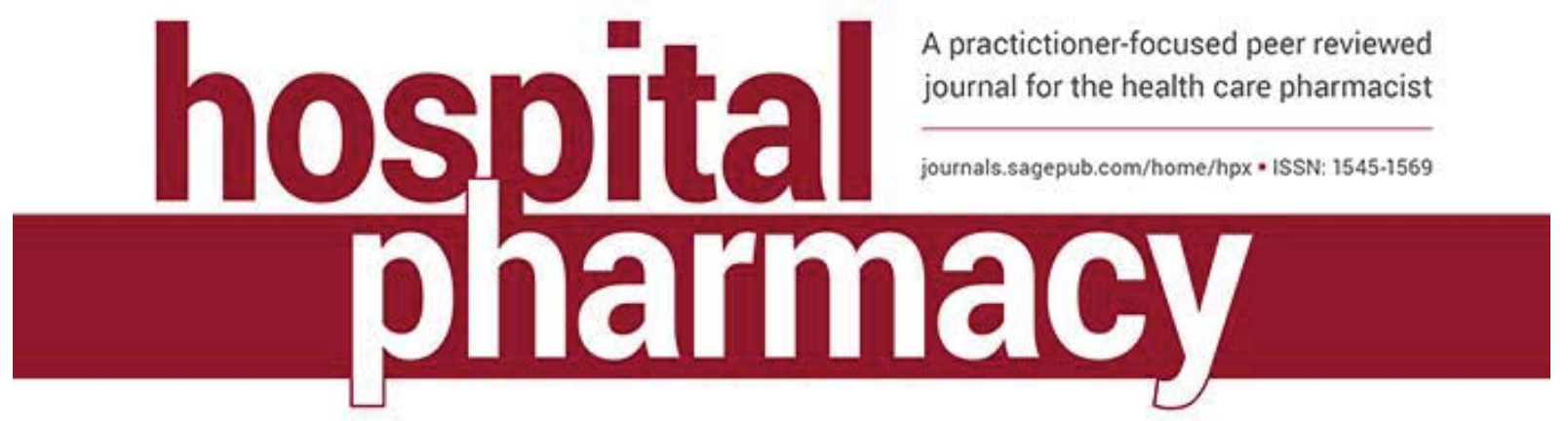

Volume 56 - Number 6 - December 2021

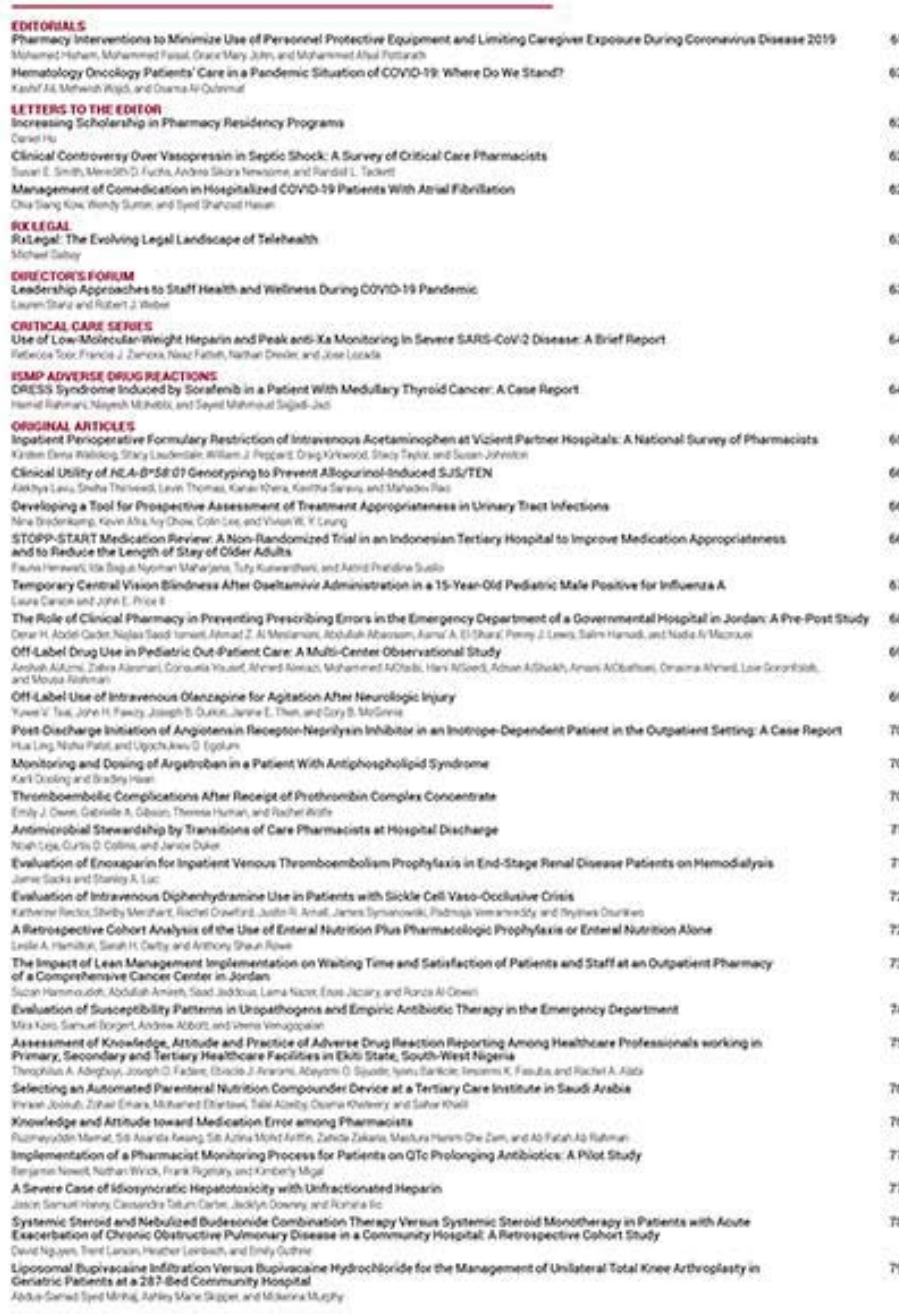




\section{SJR}

\section{Easy $\mathrm{Neo} 4 \mathrm{j}$ in One Minute}

Try Aura for a zero-admin way to bulid your applications.

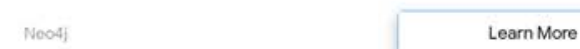

\section{Hospital Pharmacy}

\author{
COUNTRY \\ United States \\ institutions in United States
}

Journals
SUBJECT APEA AND CATEGORY

Health Professions Pharmacy

Medicine

Pharmacology (medical)

Pharmacology, Toxicology and

Pharmaceutics

Pharmacology

ISSN

00185787,19451253

\section{PUBUSHER}

Thomas Land Publishers Inc.

COVERAGE

1973-2020
H-INDEX

22

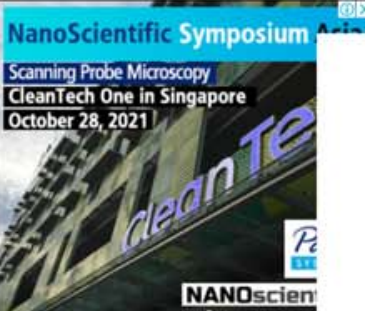

NANDscien

SCOPE

Hospital Pharmacy is a peer-reviewed journal that is practitioner-focused and dedicated to the promotion of best practices and medication safety. Turn to HPX for essential information on medication errors, adverse reaction reporting, formulary drug reviews, original research, current FDA-related drug information, off-label drug uses, new technology, and more.

Q Join the conversation about this journal

\section{Bitcoin - Tern The Page}

bitcoin promo 
FIND SIMILAR JOURNALS

American Journal of HealthSystem Pharmacy

USA

$82 \%$
similarity Journal of Pharmacy Practice USA

\section{$69 \%$}

similarity

\section{Academic Grammar Check}

Now you can know instantly if your paper is ready to submit.
Canadian Journal of Hospital Pharmacy

CAN

$56 \%$

\section{Academic Grammar Check}

5 Pharmacy

BEL

\section{$49 \%$}

American Journal Experts

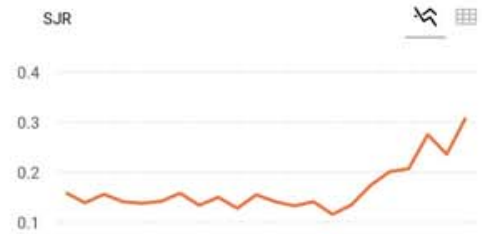

$\begin{array}{llllllll}1999 & 2002 & 2005 & 2008 & 2011 & 2014 & 2017 & 2020\end{array}$

Total Cites Self-Cites

合果

400

200

$\begin{array}{llllllll}1999 & 2002 & 2005 & 2008 & 2011 & 2014 & 2017 & 2020\end{array}$

\% International Collaboration
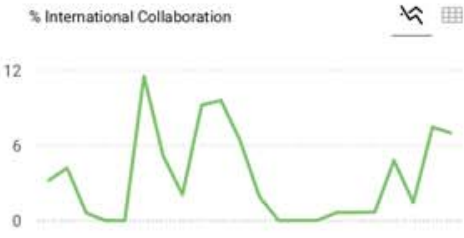

$\begin{array}{llllllll}1999 & 2002 & 2005 & 2008 & 2011 & 2014 & 2017 & 2020\end{array}$

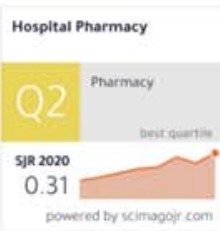

- Show this widget in your own website

Just copy the code below and paste within your htm code:

$<0$ href-"https://wwwiscim

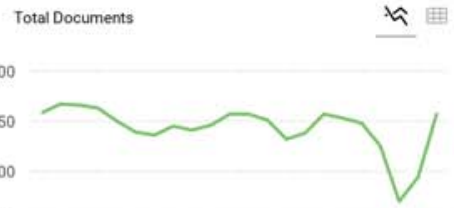

$\begin{array}{llllllll}1999 & 2002 & 2005 & 2008 & 2011 & 2014 & 2017 & 2020\end{array}$

External Cites per Doc Cites per Doc 讼

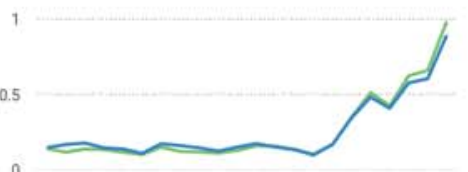

$\begin{array}{llllllll}1999 & 2002 & 2005 & 2008 & 2011 & 2014 & 2017 & 2020\end{array}$

Citable documents Non-citable documents th

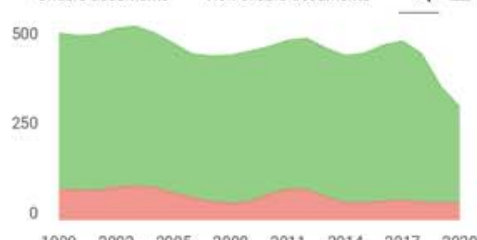

$\begin{array}{llllllll}1999 & 2002 & 2005 & 2008 & 2011 & 2014 & 2017 & 2020\end{array}$

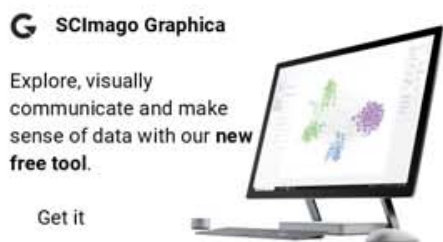

options :

$\mathrm{P}$ and $\mathrm{T}$

USA 
Metrics based on Scopus $\circledast^{\circledR}$ data as of April 2021
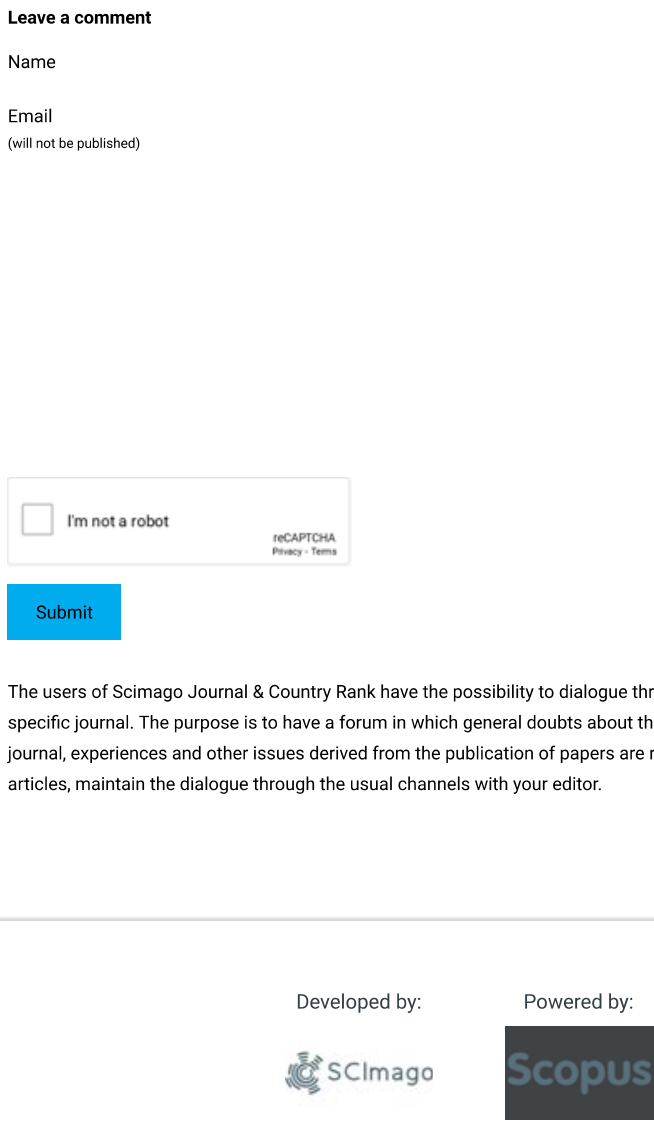

Follow us on @ScimagoJR

Scimago Lab, Copyright 2007-2020. Data Source: Scopus $®$ 


\section{Source details}

\section{Hospital Pharmacy}

Scopus coverage years: from 1973 to Present

Publisher: Thomas Land Publishers Inc.

ISSN: 0018-5787 E-ISSN: 1945-1253

Subject area: Health Professions: Pharmacy Medicine: Pharmacology (medical)

Pharmacology, Toxicology and Pharmaceutics: Pharmacology

Source type: Journal

CiteScore 2020

1.5

SJR 2020

0.309

SNIP 2020

0.567 (i)

(i)

(i)
View all documents $>$
Set document alert
$\square$ Save to source list Source Homepage

i Improved CiteScore methodology

CiteScore 2020 counts the citations received in 2017-2020 to articles, reviews, conference papers, book chapters and data papers published in 2017-2020, and divides this by the number of publications published in 2017-2020. Learn more >

CiteScore

$1.5=\frac{396 \text { Citations } 2017-2020}{264 \text { Documents } 2017-2020}$

Calculated on 05 May, 2021
CiteScoreTracker 2021 (i)

$1.2=\frac{253 \text { Citations to date }}{210 \text { Documents to date }}$

Last updated on 05 October, 2021 . Updated monthly

\section{CiteScore rank 2020 (i)}

Category Rank Percentile

Health Professions

L Pharmacy

$\# 16 / 35 \quad 55$ th

Medicine L Pharmacology $\quad \# 164 / 246 \quad 33 r d$
(medical)

Pharmacology,

Toxicology and \#218/297 26th

View CiteScore methodology $>$ CiteScore FAQ $>$ Add CiteScore to your site $\mathbb{P}$ 

About Scopus
Русский язык
Privacy matters
ELSEVIER Terms and conditions $\pi \quad$ Privacy policy $\pi$
Copyright (C) Elsevier B.V ז. All rights reserved. Scopus ${ }^{\circledR}$ is a registered trademark of Elsevier B.V.
We use cookies to help provide and enhance our service and tailor content. By continuing, you agree to the use
of cookies. 


\section{Hospital Pharmacy}

\section{Editor in Chief}

Joyce A. Generali, RPh, MS, FASHP

Clinical Professor, Emeritus

\section{Assistant Editors}

Danial E. Baker, PharmD, FASHP, FASCP

Professor of Pharmacy Practice, College of Pharmacy

Michael R. Cohen, RPh, MS, ScD, FASHP

President, Institute for Safe Medication Practices

\section{Consulting Editor}

Dennis J. Cada, PharmD, FASHP, FASCP

Executive Editor, The Formulary

\section{Editor Emeritus}

Neil M. Davis, MS, PharmD, FASHP

President, Safe Medication Practices Consulting, Inc.

\section{Editorial Advisory Board}

Yousef Alomi, BSC, MS, BCPS, BCNSP, DIBA, CDE

Head, National Clinical Pharmacy and Pharmacy Practice Programs

Debra S. Devereaux, MBA, FASHP

Vice President, Pharmacy

Kate Farthing, PharmD, BCPS, FASHP

Pharmacy Clinical Coordinator, Legacy Salmon Creek Medical Center

Harold Godwin, MS, RPh, FASHP

Kansas University Medical Center

Terri L. Levien, PharmD

Washington State University Spokane

Sondra K. May, PharmD

University of Colorado

Barbara Poe, BS, MBA

Norman Regional Hospital

Terry S. Smith, RPh, MS

McKesson Pharmacy Optimization

Jacyntha A. Sterling, PharmD

Saint Francis Hospital, Tulsa, Oklahoma

Burgunda V. Sweet, PharmD

University of Michigan Healthcare System 


\section{Contents}

\section{Editorials}

Pharmacy Interventions to Minimize Use of Personnel Protective Equipment and Limiting Caregiver

Exposure During Coronavirus Disease 2019

Mohamed Hisham, Mohammed Faisal, Grace Mary John, and Mohammed Afsal Pottarath

Hematology Oncology Patients' Care in a Pandemic Situation of COVID- 19: Where Do We Stand?

Kashif Ali, Mehwish Wajdi, and Osama Al-Quteimat

\section{Letters to the Editor}

Increasing Scholarship in Pharmacy Residency Programs

Daniel $\mathrm{Hu}$

Clinical Controversy Over Vasopressin in Septic Shock: A Survey of Critical Care Pharmacists

Susan E. Smith, Meredith D. Fuchs, Andrea Sikora Newsome, and Randall L. Tackett

Management of Comedication in Hospitalized COVID-19 Patients With Atrial Fibrillation

Chia Siang Kow, Wendy Sunter, and Syed Shahzad Hasan

\section{Rx Legal}

RxLegal: The Evolving Legal Landscape of Telehealth

Michael Gabay

\section{Director's Forum}

Leadership Approaches to Staff Health and Wellness During COVID-I 9 Pandemic

Lauren Stanz and Robert J. Weber

\section{Critical Care Series}

Use of Low-Molecular-Weight Heparin and Peak anti-Xa Monitoring In Severe SARS-CoV-2 Disease: A Brief Report

Rebecca Toor, Francis J. Zamora, Naaz Fatteh, Nathan Drexler, and Jose Lozada

\section{ISMP Adverse Drug Reactions}

DRESS Syndrome Induced by Sorafenib in a Patient With Medullary Thyroid Cancer: A Case Report

Hamid Rahmani, Niayesh Mohebbi, and Sayed Mahmoud Sajadi-Jazi

\section{Original Articles}

Inpatient Perioperative Formulary Restriction of Intravenous Acetaminophen at Vizient Partner Hospitals:

A National Survey of Pharmacists

Kirsten Elena Wallskog, Stacy Lauderdale, William J. Peppard, Craig Kirkwood, Stacy Taylor, and Susan Johnston

Clinical Utility of HLA-B*58:0I Genotyping to Prevent Allopurinol-Induced SJS/TEN

Alekhya Lavu, Sneha Thiriveedi, Levin Thomas, Kanav Khera, Kavitha Saravu, and Mahadev Rao

Developing a Tool for Prospective Assessment of Treatment Appropriateness in Urinary Tract Infections

Nina Bredenkamp, Kevin Afra, Ivy Chow, Colin Lee, and Vivian W. Y. Leung

STOPP-START Medication Review: A Non-Randomized Trial in an Indonesian Tertiary Hospital to Improve

Medication Appropriateness and to Reduce the Length of Stay of Older Adults

Fauna Herawati, Ida Bagus Nyoman Maharjana, Tuty Kuswardhani, and Astrid Pratidina Susilo

Temporary Central Vision Blindness After Oseltamivir Administration in a 15-Year-Old Pediatric Male

Laura Carson and John E. Price II 
The Role of Clinical Pharmacy in Preventing Prescribing Errors in the Emergency Department of a

Governmental Hospital in Jordan: A Pre-Post Study

Derar H. Abdel-Qader, Najlaa Saadi Ismael, Ahmad Z. Al Meslamani, Abdullah Albassam, Asma' A. El-Shara', Penny J. Lewis,

Salim Hamadi, and Nadia Al Mazrouei

Off-Label Drug Use in Pediatric Out-Patient Care: A Multi-Center Observational Study

Aeshah AlAzmi, Zahra Alasmari, Consuela Yousef, Ahmed Alenazi, Mohammed AlOtaibi, Hani AlSaedi, Adnan AlShaikh,

Amani AlObathani, Omaima Ahmed, Loie Goronfolah, and Mousa Alahmari

Off-Label Use of Intravenous Olanzapine for Agitation After Neurologic Injury

Yuwei V. Tsai, John H. Fawzy, Joseph B. Durkin, Janine E. Then, and Cory B. McGinnis

Post-Discharge Initiation of Angiotensin Receptor-Neprilysin Inhibitor in an Inotrope-Dependent Patient

in the Outpatient Setting: A Case Report

Hua Ling, Nisha Patel, and Ugochukwu O. Egolum

Monitoring and Dosing of Argatroban in a Patient With Antiphospholipid Syndrome

Karli Dooling and Bradley Haan

Thromboembolic Complications After Receipt of Prothrombin Complex Concentrate

Emily J. Owen, Gabrielle A. Gibson, Theresa Human, and Rachel Wolfe

Antimicrobial Stewardship by Transitions of Care Pharmacists at Hospital Discharge

Noah Leja, Curtis D. Collins, and Janice Duker

Evaluation of Enoxaparin for Inpatient Venous Thromboembolism Prophylaxis in End-Stage Renal Disease

Patients on Hemodialysis

Jamie Sacks and Stanley A. Luc

Evaluation of Intravenous Diphenhydramine Use in Patients with Sickle Cell Vaso-Occlusive Crisis

Katherine Rector, Shelby Merchant, Rachel Crawford, Justin R. Arnall, James Symanowski, Padmaja Veeramreddy, and Ifeyinwa Osunkwo

A Retrospective Cohort Analysis of the Use of Enteral Nutrition Plus Pharmacologic Prophylaxis or

Enteral Nutrition Alone

Leslie A. Hamilton, Sarah H. Darby, and Anthony Shaun Rowe

The Impact of Lean Management Implementation on Waiting Time and Satisfaction of Patients and Staff at an Outpatient Pharmacy of a Comprehensive Cancer Center in Jordan

Suzan Hammoudeh, Abdullah Amireh, Saad Jaddoua, Lama Nazer, Enas Jazairy, and Ronza Al-Dewiri

Evaluation of Susceptibility Patterns in Uropathogens and Empiric Antibiotic Therapy in the Emergency Department Mira Koro, Samuel Borgert, Andrew Abbott, and Veena Venugopalan

Assessment of Knowledge, Attitude and Practice of Adverse Drug Reaction Reporting Among Healthcare Professionals working in Primary, Secondary and Tertiary Healthcare Facilities in Ekiti State, South-West Nigeria Theophilus A. Adegbuyi, Joseph O. Fadare, Ebisola J. Araromi, Abayomi O. Sijuade, lyanu Bankole, llesanmi K. Fasuba, and Rachel A. Alabi

Selecting an Automated Parenteral Nutrition Compounder Device at a Tertiary Care Institute in Saudi Arabia Imraan Joosub, Zohair Emara, Mohamed Eltantawi, Talal Alzeiby, Osama Khateery, and Sahar Khalil

Knowledge and Attitude toward Medication Error among Pharmacists

Ruzmayuddin Mamat, Siti Asarida Awang, Siti Azlina Mohd Ariffin, Zahida Zakaria, Mastura Hanim Che Zam, and Ab Fatah Ab Rahman

Implementation of a Pharmacist Monitoring Process for Patients on QTc Prolonging Antibiotics: A Pilot Study

Benjamin Newell, Nathan Wirick, Frank Rigelsky, and Kimberly Migal

A Severe Case of Idiosyncratic Hepatotoxicity with Unfractionated Heparin

Jason Samuel Haney, Cassandra Tatum Carter, Jacklyn Downey, and Romina llic

Systemic Steroid and Nebulized Budesonide Combination Therapy Versus Systemic Steroid Monotherapy

in Patients with Acute Exacerbation of Chronic Obstructive Pulmonary Disease in a Community Hospital:

A Retrospective Cohort Study

David Nguyen, Trent Larson, Heather Leinbach, and Emily Guthrie

Liposomal Bupivacaine Infiltration Versus Bupivacaine Hydrochloride for the Management of Unilateral

Total Knee Arthroplasty in Geriatric Patients at a 287-Bed Community Hospital

Abdus-Samad Syed Minhaj, Ashley Marie Skipper, and Mckenna Murphy 